\title{
Diagnosing COPD: High Time for a Paradigm Shift
}

In this issue of Respiratory CARe, Vaz Fragoso et al ${ }^{1}$ and Aggarwal et $\mathrm{al}^{2}$ make important contributions to the ongoing discussion on how to properly diagnose COPD. Let us put the problem in perspective.

SeE the Original Studies on Pages 1771 and 1778

In the past there was a growing concern that many cases of COPD went undetected and that generally too little effort was spent in diagnosing COPD, a disease syndrome relatively unknown to the public, or to public health and government officials. Because of this, the United States National Heart, Lung, and Blood Institute and the World Health Organization formed the Global Initiative for Chronic Obstructive Lung Disease (GOLD), ${ }^{3}$ which issued recommendations for diagnosing and managing COPD. Spirometrically-determined airflow limitation was proposed as the key measurement for identifying COPD. The definition of airflow limitation, however, still leads to controversy.

An abnormally low ratio of $\mathrm{FEV}_{1}$ to $\mathrm{FVC}$ is universally accepted as indicating airflow limitation: the hallmark of COPD. In adults the $\mathrm{FEV}_{1}, \mathrm{FVC}$, and $\mathrm{FEV}_{1} / \mathrm{FVC}$ fall with age, and not at the same rate for men and women. Therefore, various organizations ${ }^{4-7}$ have recommended using the lower fifth percentile from a population of healthy neversmokers as the lower limit of normal (LLN). Hence, an $\mathrm{FEV}_{1} / \mathrm{FVC}<\mathrm{LLN}$ is compatible with airflow limitation. This approach is scientifically valid and in keeping with the way results from the chemistry laboratory have been interpreted for decades in clinical practice. However, despite the widespread availability of computers that can perform the calculation, the GOLD committee judged that using the LLN was too complicated for doctors and recommended a fixed $\mathrm{FEV}_{1} / \mathrm{FVC}$ of 0.70 as the cutoff for diagnosing COPD. They also recommended the use of percent-of-predicted $\mathrm{FEV}_{1}$, with $80 \%$ separating mild from moderately severe COPD. In healthy subjects the LLN for $\mathrm{FEV}_{1} / \mathrm{FVC}$ falls well below 0.70 above age 45 years, so the fixed-ratio method $\left(\mathrm{FEV}_{1} / \mathrm{FVC}<0.70\right)$ is heavily biased by age, and to a lesser extent by height, sex, and, possibly, ethnic group. The use of $\mathrm{FEV}_{1}<80 \%$ of predicted, probably first advocated by Bates and Christie, ${ }^{8}$ has similarly been shown to be highly biased by age..$^{9,10}$ More than 30 years ago, Sobol wrote: "Nowhere else in medicine is such a naïve view taken of the limit of normal."11

Hardie et al $^{12}$ were the first to point out the massive (up to $50 \%$ ) over-diagnosis of COPD in elderly healthy neversmokers that can occur with the fixed ratio. Many other authors subsequently confirmed this, and pointed out that the fixed ratio also leads to under-diagnosis in younger subjects. ${ }^{13}$ Essentially, the disagreement is about interpreting an $\mathrm{FEV}_{1} / \mathrm{FVC}<0.70$ but $>$ LLN. If such a ratio could be shown to entail a higher risk of premature death, hospitalization, or other ill health effects, that would end the discussion in favor of the GOLD guidelines. So far, however, all the published evidence points the other way. In a literature review, Hoesein et al $^{14}$ compared subjects with an $\mathrm{FEV}_{1} / \mathrm{FVC}<0.70$ but $>$ LLN to those with normal lung function, and posited that LLN might miss subjects at risk of hospitalization and death. Their conclusion hinged exclusively on a paper by Mannino et al, ${ }^{15}$ who found that GOLD stage 1 was associated with higher risk of premature death. However, Mannino et al misinterpreted their own results: the adjusted odds ratio (CI 0.96-1.3) was not different from that in healthy controls. Their reported increased hazard ratio for hospitalization ${ }^{15}$ also failed under scrutiny, as Mannino et al conceded that "the measure of COPD-related hospitalizations was too inclusive." 16 Thus, Hoesein's conclusion ${ }^{14}$ also collapses. Recently, this same flaw crept into another study, ${ }^{17}$ which found that about $34 \%$ of a cohort who had at least one hospital admission for COPD did not meet the spirometric definition of COPD prior to hospitalization. Curiously, rather than concluding that this underlines the severe limitations of using administrative data ${ }^{18,19}$ confounded by cardiovascular and other diseases, Garcia-Aymerich et al concluded that GOLD stage 1 represents an increased risk of COPD hospitalization and subsequent mortality. ${ }^{17}$ An administrative or hospital diagnosis of COPD can be very biased, again appearing to be too inclusive, ${ }^{16}$ and does not warrant that conclusion.

The relative risk of death in GOLD stage 1 in a Swedish population was elevated in female smokers, but not in men, and not in female and male former or never smokers. ${ }^{20}$ After adjustment for potential confounders, the hazard ratio for all-cause mortality in older participants in the National Health and Nutrition Examination Survey III was significantly elevated only at an $\mathrm{FEV}_{1}<5$ th percentile, regardless of GOLD stage, ${ }^{21}$ and GOLD stage 1 was not 
associated with a higher prevalence of respiratory symptoms. Compared to the percentile approach, the risk of death and of respiratory symptoms in subjects with GOLD stage 2 was also poorly classified, ${ }^{21}$ which confirmed a previous report ${ }^{22}$ that the GOLD criteria were not adequate for correctly placing individual subjects into disease stage categories that relate to survival. GOLD stage 1 in asymptomatic subjects is not associated with dyspnea, accelerated $\mathrm{FEV}_{1}$ decline, respiratory care utilization, or qualityof-life scores, compared to a reference group. ${ }^{23}$ In a clinical population there is bound to be less misdiagnosis than in a normal population, because of the higher disease prevalence. In Aggarwal et al's study, ${ }^{2}$ which compares the fixed ratio to the LLN in a large male clinical population, the fixed ratio underestimated the prevalence of airflow limitation by $13 \%$ in the $21-40$-year age range, and overestimated it by $16 \%$ in the $40-95$ year age range. In another large clinical study, $24 \%$ were misclassified by the fixed ratio. ${ }^{24}$

There is no high-quality evidence that an $\mathrm{FEV}_{1} /$ FVC $<0.7$ but $>5$ th percentile represents disease, or increased risk of death. Conversely, values below the 5th percentile do imply increased risk. Vaz Fragoso et al raised the bar by substituting the biased fixed ratio ${ }^{25}$ with a novel technique, the lambda-mu-sigma method with the lower limit of normal as the 5th percentile of the distribution of $\mathrm{Z}$ scores $\left(\mathrm{LMS}-\mathrm{LLN}_{5}\right.$ ), pioneered by Stanojevic et al. ${ }^{26,27}$ This method takes into account that the relationship between the predictor variables (eg, age, height, sex) and spirometry measurements is not linear, and that reference values are not normally distributed and do not have constant variability. They found that only individuals with an $\mathrm{FEV}_{1} / \mathrm{FVC}$ less than $\mathrm{LMS}^{-L_{L} N_{5}}$ had a higher risk of allcause mortality and higher prevalence of respiratory symptoms. Vaz Fragoso et $\mathrm{al}^{1}$ found that in 2 cohorts of white older patients within the National Health and Nutrition Examination Survey III and the Atherosclerosis Risk In Communities study, the cutoffs that were associated with a significantly higher risk of respiratory symptoms and death were an $\mathrm{FEV}_{1} / \mathrm{FVC}$ below the $\mathrm{LMS} \mathrm{LLN}_{5}$, and a reduced $\mathrm{FVC}\left(\mathrm{FEV}_{1} / \mathrm{FVC}>\mathrm{LMS}^{\mathrm{LLLN}} \mathrm{L}_{5}\right.$ and $\mathrm{FVC}<\mathrm{LMS}-$ $\mathrm{LLN}_{5}$ ), which suggests restrictive-pattern rather than airflow limitation.

Arising from published evidence, a letter from 152 scientists and clinicians and 13 organizations requested that the GOLD guidelines be modified. ${ }^{28,29}$ The GOLD committee has acknowledged that the fixed ratio leads to overdiagnosis and misclassification, ${ }^{3}$ but argued that the frequent use of the guidelines justifies leaving them unchanged, ${ }^{30,31}$ disregarding clinical evidence. If we accept that GOLD stage 1 does not represent respiratory disease (as discussed above), it is not surprising that no evidence has been published to show that any intervention, other than smoking cessation, has any effect. In a recently published guideline, the initiation of inhaled bronchodilator in patients who have respiratory symptoms is therefore recommended only if $\mathrm{FEV}_{1}$ is $<60 \%$ of predicted. ${ }^{32} \mathrm{In}$ deed, the low $\mathrm{FEV}_{1}$ - and not $\mathrm{FEV}_{1} / \mathrm{FVC}$ - has been shown to be a very significant risk factor for death. ${ }^{33-36}$

That international societies issue disparate guidelines, advocating both the fixed ratio ${ }^{32}$ and the LLN, ${ }^{4-6}$ is an important impediment to progress in COPD research, leads to subject-selection bias, and wastes money and resources. More extensive use of spirometry is needed to detect airflow limitation, but guidelines should not cause any patients to be incorrectly diagnosed with COPD, which imposes the psychological burden of a disease with a poor prognosis.

Philip H Quanjer MD PhD Department of Pulmonary Diseases and Department of Paediatrics Erasmus Medical Centre Erasmus University Rotterdam, The Netherlands

Gregg L Ruppel MEd RRT RPFT FAARC Pulmonary Function Laboratory Saint Louis University Hospital St Louis, Missouri

\section{REFERENCES}

1. Vaz Fragoso CA, Gill TM, McAvay G, Van Ness PH, Yaggi HK, Concato J. Use of lambda-mu-sigma-derived z score for evaluating respiratory impairment in middle-aged persons. Respir Care 2011; 56(11):1771-1777

2. Aggarwal AN, Gupta D, Agarwal R, Jindal SK. Comparison of the lower confidence limit to the fixed-percentage method for assessing airway obstruction in routine clinical practice. Respir Care 2011; 56(11):1778-1784.

3. Global Initiative for Chronic Obstructive Lung Disease. Global Strategy for Diagnosis, Management and Prevention of COPD. Update 2010. http://www.goldcopd.org/guidelines-global-strategy-fordiagnosis-management.html. Accessed September 7, 2011.

4. American Thoracic Society. Lung function testing: selection of reference values and interpretative strategies. Am Rev Respir Dis 1991; 144(5 part 1):1202-1218.

5. Quanjer PH, Tammeling GJ, Cotes JE, Pedersen OF, Peslin R, Yernault J-C. Lung volumes and forced ventilatory flows. Report Working Party Standardization of Lung Function Tests, European Community for Steel and Coal, Official Statement of the European Respiratory Society. Eur Respir J 1993;6(Suppl 16):5-40.

6. Miller MR, Hankinson J, Brusasco V, Burgos F, Casaburi R, Coates A, et al; ATS/ERS Task Force. Standardisation of spirometry. Eur Respir J 2005;26(2):319-338.

7. Levy ML, Quanjer PH, Booker R, Cooper BG, Holmes S, Small I. Diagnostic spirometry in primary care: proposed standards for general practice compliant with American Thoracic Society and European Respiratory Society recommendations: a General Practice Airways Group (GPIAG) document, in association with the Association 


\section{Diagnosing COPD: High Time for a Paradigm Shift}

for Respiratory Technology \& Physiology (ARTP) and Education for Health. Prim Care Respir J 2009;18(3):130-147.

8. Bates, DV, Christie RV. Respiratory function in disease. Philadelphia: Saunders; 1964:91

9. Sobol BJ. Assessment of ventilatory abnormality in the asymptomatic subject: an exercise in futility. Thorax 1966;21(5):445-449.

10. Miller MR, Pincock AC. Predicted values: how should we use them? (editorial) Thorax 1988;43(4):265-267.

11. Sobol BJ, PG Sobol. Per cent of predicted as the limit of normal in pulmonary function testing: a statistically valid approach (editorial). Thorax 1979;34(1):1-3.

12. Hardie JA, Buist AS, Vollmer WM, Ellingsen I, Bakke PS, Mørkve O. Risk of over-diagnosis of COPD in asymptomatic elderly neversmokers. Eur Respir J 2002;20(5):1117-1122.

13. Cerveri I, Corsico AG, Accordini S, Niniano R, Ansaldo E, Antó JM, et al. Underestimation of airflow obstruction among young adults using $\mathrm{FEV}_{1} / \mathrm{FVC}<70 \%$ as a fixed cut-off; a longitudinal evaluation of clinical and functional outcomes. Thorax 2008;63(12):1040-1045.

14. Hoesein FAAM, Zanen P, Lammers J-WJ. Lower limit of normal or $\mathrm{FEV}_{1} / \mathrm{FVC}<0.70$ in diagnosing COPD: an evidence-based review. Respir Med 2011;105(6):907-915.

15. Mannino DM, Buist AS, Vollmer WM. Chronic obstructive pulmonary disease in the older adult: what defines abnormal lung function? Thorax 2007;62(3):237-241.

16. Mannino DM, Buist AS, Vollmer WM. Authors' reply to two letters to the editor. Thorax 2007;62(12):1108-1109.

17. Garcia-Aymerich J, Pons IS, Mannino DM, Maas AK, Miller DP, Davis KJ. Lung function impairment, COPD hospitalisations and subsequent mortality. Thorax 2011;66(7):85-590.

18. Mannino DM. Understanding COPD hospitalizations: the devil is always in the details! Chest 2007;132(60):1731-1732.

19. Damarla M, Celli BR, Mullerova HX, Pinto-Plata VM. Discrepancy in the use of confirmatory tests in patients hospitalized with the diagnosis of chronic obstructive pulmonary disease or congestive heart failure. Respir Care 2006;51(10):1120-1124.

20. Ekberg-Aronsson M, Pehrsson K, Nilsson JÅ, Nilsson PM, Löfdahl CG. Mortality in GOLD stages of COPD and its dependence on symptoms of chronic bronchitis. Respir Res 2005;6(1):98.

21. Vaz Fragoso CA, Concato J, McAvay G, Van Ness PH, Rochester CL, Klar Yaggi H, Gill TM. Chronic obstructive pulmonary disease in older persons: a comparison of two spirometric definitions. Respir Med 2010;104(8):1189-1196.

The authors have disclosed no conflicts of interest.

Correspondence: Philip H Quanjer MD PhD. E-mail: pquanjer@xs4all.nl.

DOI: $10.4187 /$ respcare. 01590
22. Miller MR, Pedersen OF, Dirksen A. A new staging strategy for chronic obstructive pulmonary disease. Int J Chron Obstruct Pulmon Dis 2007;2(4):657-663.

23. Bridevaux PO, Gerbase MW, Probst-Hensch NM, Schindler C, Gaspoz JM, Rochat T. Long-term decline in lung function, utilisation of care and quality of life in modified GOLD stage 1 COPD. Thorax 2008;63(9):768-774.

24. Miller MR, Quanjer PH, Swanney MP, Ruppel G, Enright PL. Interpreting lung function data using $80 \%$ predicted and fixed thresholds misclassifies more than 20\% of patients. Chest 2011;139(1):5259.

25. Vaz Fragoso CA, Concato J, McAvay G, Van Ness PH, Rochester C, Klar Yaggi H, Gill TM. The ratio of forced expiratory volume in 1 -second to forced vital capacity as a basis for establishing chronic obstructive pulmonary disease. Am J Respir Crit Care Med 2010; 181(5):446-451.

26. Stanojevic S, Wade A, Stocks J, Hankinson J, Coates AL, Pan H, et al. Reference ranges for spirometry across all ages. Am J Respir Crit Care Med 2008;177(3):253-260.

27. Stanojevic S, Wade A, Stocks J. Reference values for lung function: past, present and future. Eur Respir J 2010;36(1):12-19.

28. Quanjer PH, Enright PL, Ruppel G. The GOLD guidelines definition of mild airway obstruction. Respir Care 2010;55(10):1397-1398.

29. Quanjer PH, Enright PL, Miller MR, Stocks J, Ruppel G, Swanney MR, et al. The need to change the method for defining mild airway obstruction. Eur Respir J 2011;37(3):720-722.

30. Vestbo J, Rodriguez-Roisin R. GOLD and the fixed ratio. Eur Respir J 2011;38(2):481-482.

31. Quanjer PH, Enright PL, Ruppel G, Miller MR, Vaz Fragoso CA, Cooper BG, et al. GOLD and the fixed ratio. Eur Respir J 2011; 38(2):482-483.

32. Qaseem A, Wilt TJ, Weinberger SE, Hanania NA, Criner G, van der Molen $\mathrm{T}$, et al. Diagnosis and management of stable chronic obstructive pulmonary disease: a clinical practice guideline update from the American College of Physicians, American College of Chest Physicians, American Thoracic Society, and European Respiratory Society. Ann Intern Med 2011;155(3):179-191.

33. Sorlie PD, Kannel WB, O'Connor G. Mortality associated with respiratory function and symptoms in advanced age. The Framingham Study. Am Rev Respir Dis 1989;140(2):379-384.

34. Hole DJ, Watt GCM, Davey-Smith G, Hart CL, Gillis CR, Hawthorne VM. Impaired lung function and mortality risk in men and women: findings from the Renfrew and Paisley prospective population study. BMJ 1996;313(7059):711-715.

35. Knuiman MW, James AL, Divitini ML, Ryan G, Bartholomew HC, Musk AW. Lung function, respiratory symptoms, and mortality: results from the Busselton health study. Ann Epidemiol 1999;9(5): 297-306.

36. Sin DD, Wu LL, Paul Man SFP. The relationship between reduced lung function and cardiovascular mortality. A population-based study and a systematic review of the literature. Chest 2005;127(6):19521959. 